POLLACK PERIODICA

An International Journal for Engineering and Information Sciences

DOI: $10.1556 / 606.2018 .13 .1 .19$

Vol. 13, No. 1, pp. 217-224 (2018)

www.akademiai.com

\title{
PROBLEMS OF SURVEYING PROFILE SHAPES OF GOTHIC ARCHITECTURAL FRAGMENTS
}

\author{
${ }^{1}$ Krisztina FEHÉR, ${ }^{2}$ Balázs HALMOS \\ Department for History of Architecture and of Monument, Faculty of Architecture \\ Budapest University of Technology and Economics, Müegyetem rkp. 3, H-1111 Budapest \\ Hungary, e-mail: ${ }^{1}$ feher.krisztina@eptort.bme.hu, ${ }^{2}$ halmos@eptort.bme.hu
}

Received 4 January 2017; accepted 12 September 2017

\begin{abstract}
The quest for the secret of geometric design methods and proportioning strategies of medieval master builders dates back to the middle of the $19^{\text {th }}$ century. The improvement of surveying technologies allows adapting the advantages of laser-based instruments and computer aided analysis to the observation of this subject of revolving relevance. The subject of the paper research is to present the analysis of medieval architectural details from a geometrical point of view. In the current status of the research the paper focuses on the methodological aspects of the surveying process of gothic architectural fragments.
\end{abstract}

Keywords: Gothic architecture, Medieval design, Geometry, Survey

\section{Introduction}

The designing method of medieval stonemasons can be discovered by studying architectural texts and illustrations of architectural treatises or examining remaining structural elements. The contemporary depictions of medieval stone carvers, for instance in the Bedford Hours or the Grandes Chroniques de France show the process of tracing stone elements as well as the tools utilized. The sketchbook of Villard de Honnecourt contains the drawings of several architectural details with technical hints concerning their realization. The Unterweisung of Lorenz Lechler, as an actual handbook of medieval architecture, also provides advice on how to create carved structural elements while the sketchbook of Hans Hammer contains ideal and real drawings of complicated structures [1]. In these sources the drawn profiles next to the texts are more likely to represent templates then the carved stone elements themselves 
[2], [3] (Fig. 1). The subject of architectural design in medieval times has numerous unanswered questions regarding both whole buildings and details. Despite the remaining cathedral plans and elevations, as well as the subsisting evidences of drafting like the tracing house of York Minster and Wells Cathedral [4] or structural sketches left on medieval walls (as in Batalha and Jerónimos Monasteries in Portugal, (Fig. 2) or the couple of sketches recently discovered during restitution works in the Calvinist Church of Cluj-Napoca) the research of this topic still has to deal with plenty of problems. Despite of the fact that a considerable amount of Gothic architectural plans is known [5], several questions of the design process are still opened. However these remaining drawings are often of high complexity, they are rarely related to the design of structural details such as the elements of vaulting.

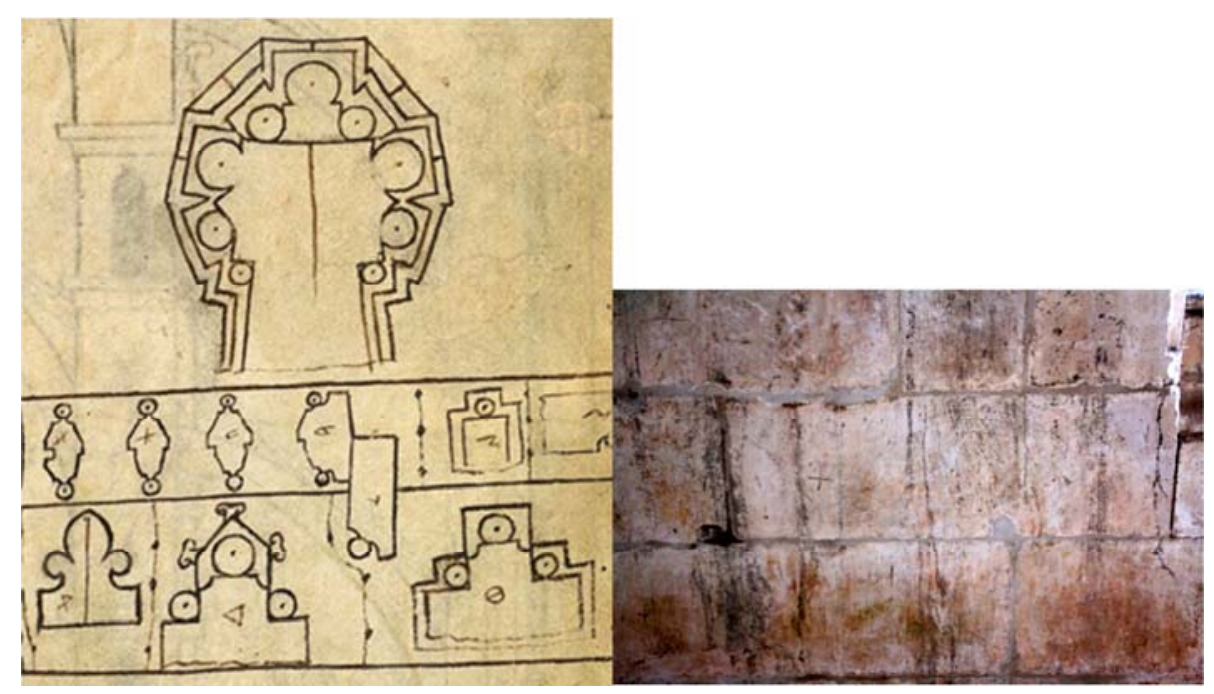

Fig. 1. Illustration of profiles in the Sketchbook of Villard de Honnecourt [6]
Fig. 2. Constructing traces left by medieval masons on the cloister wall of Batalha Monastery (Batalha, Portugal) (Authors' photo)

One of the $\mathrm{PhD}$ research programs of Csonka Pál Doctoral School of Budapest University of Technology and Economics titled 'Geometric Aspects of Gothic Architectural Details' is focusing on the accurate examination of profiled carved stones originating from the medieval Royal Palace of Buda Castle. Below the summary of methodological experiences of a case study of surveying four gothic fragments will be presented.

\section{Description of the case study}

The case study was based on the survey of four profiled stones selected from the medieval stone collection of the Budapest History Museum, which were excavated from 
the former Royal Castle of Buda (Budapest, Hungary). This stone collection consists of the remaining decorative structural elements of the former gothic periods of the royal residence as well as the surrounding buildings in the Buda Castle Hill from the era of Louis I (1342-1382), Sigismund of Luxemburg (1387-1437), Vladislaus II (1490-1516) and Matthias Corvinus I (1458-1490), [7].

An unpublished catalogue and topographic systematization of the collection related to the royal palace was created by Emese Nagy in 1994 [8], but to fulfil the requirements of the present $\mathrm{PhD}$ research a new catalogue was initiated. The four carved stones selected to be measured have the reference numbers \#0048, \#0051, \#0068 and \#0121 in the catalogue. Aspects considered while selecting the four items were the diversity of their one-time structural role, material, dimensions, shape and condition.

The stone \#0048 is a general rib element probably from a cross rib vault. The profile consists of a main upper molding and two smaller on both sides followed by gouges. It is considered to be typical in Buda in the first half of the $16^{\text {th }}$ century [9]. Regarding its condition this is the most fragmentary of the four items, but the profile is still recognizable. This stone serves an interesting example as its curved directrix is clearly visible. Its limestone material is quite easily weathering (Fig. 3a).

The item \# 0051 presumably served as a rib element of probably a lierne vault (accounted by its quite small scale), however it might be an unfinished piece. Dating is uncertain. The upper part of the profile is in a good condition due to its porous limestone material. The oblique jointing surface of the fragment is of special importance as it preserved the scratched lines of the master tracing the main guidelines of the profile construction (Fig. $3 b$ ).

The stone \#0068 is also a rib element. The shape of its profile after its double upper molding - is mostly sharp despite of its several fractured parts. Presumably an early $16^{\text {th }}$ century form similarly to \#0048 [9]. As its material is porous limestone, the traces held by stone carvers' tools can be seen on its surfaces. (Fig. 3c).

The item \#0121 is a mullion element that differs from the other three in several aspects. According to its constructional role, its material (travertine) is much harder than the rocks typically used for the vaulting elements. Dating of the piece is uncertain. Because of the solidity of the massive limestone material carving is more laborious and the moldings are mostly unscathed (Fig. $3 d$ ).

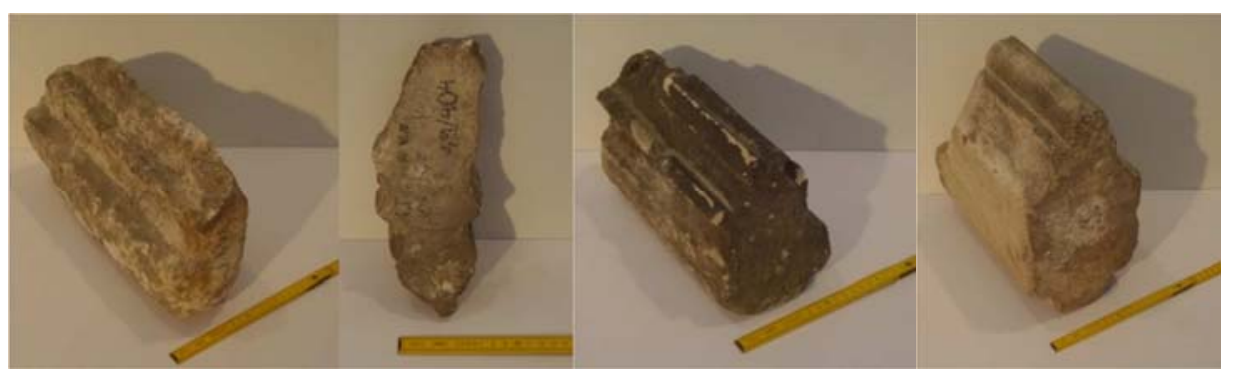

a)

b)

c)

d)

Fig. 3. The fragments of the case study: a) Profiled rib element \#0048; b) Profiled rib element \#0051; c) Profiled rib element \#0068; d) Profiled mullion element \#0121 (Authors' photo) 
The fundamental aim of studying these objects was to detect the method used for constructing the profiles, thus to reveal the geometric principles followed by certain stonemasons of the middle ages. To analyze these principles an ideal scheme of the profile is to be presented. The reconstruction of the profile desired by the master after surveying the element precisely is far from obvious. Several aspects have to be considered for example the accuracy of the carving process, the abrasion of the piece or the deviations of the measuring itself. Each of these factors allows a margin on a cm scale, which can extend $5 \%$ of imprecision, significant enough to affect the plausibility of the construction grid suggested. Therefor all these aspects have to be considered carefully while choosing the proper survey method, designing the measurement process itself and processing the data obtained.

Although the measurement technologies have been considerably advanced, the traditional manual way of survey is still the most common method of measuring carved stone details. Drawing the item by hand as the first step of the survey, its shape and character can be learnt in details. This orthogonal manual drafting is the basis of the measurement. In the case of the four gothic stones, cross sectional drawings were needed as the further research focuses on the examination of the profiles (Fig. 4). The manuals, the measure and the creation of CAD drawings of the profiles (Fig. 5) have taken altogether approximately three and a half hours.

Survey methods based on 3D modeling technologies - structured light scanning, terrestrial laser scanning, depth camera and image-based reconstruction - are certainly of high standard benefits regarding the accuracy of the outcome and the time rate of the process [10]. They also provide the possibility of ideal reconstructions and analysis of whole structural systems. [11], [12]. These methods however miss the direct interaction between researcher and object, which is of high importance especially in the case of architectural details. Laser based total station survey is potentially appropriate to fulfill the requirements of both accuracy and time-saving while the data acquisition is still led by the researcher.

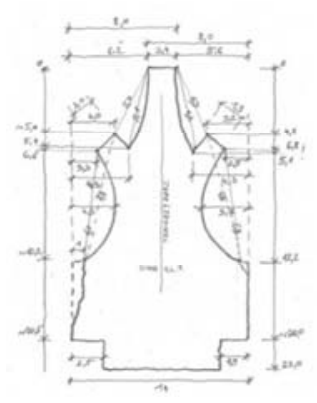

a)

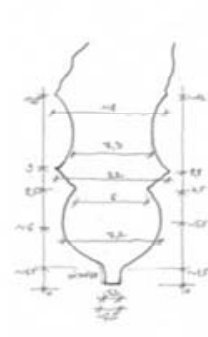

b)

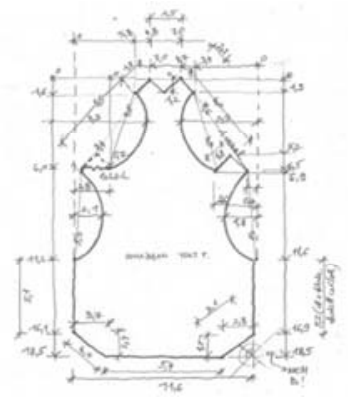

c)

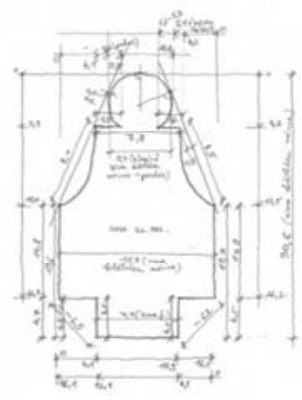

d)

Fig. 4. Manual drawings of the four gothic fragments: a) Profiled rib element \#0048;

b) Profiled rib element \#0051; c) Profiled rib element \#0068; d) Profiled mullion element \#0121 (Authors' drawings) 


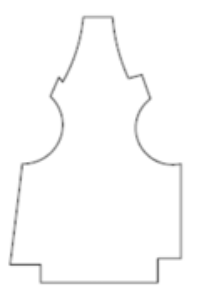

a)

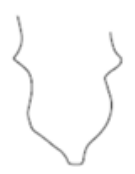

b)

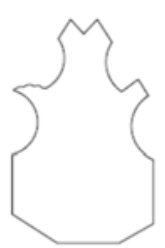

c)

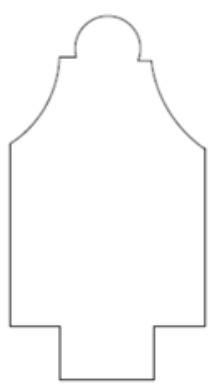

d)

Fig. 5. CAD drawings of the four gothic fragments: a) Profiled rib element \#0048;

b) Profiled rib element \#0051; c) Profiled rib element \#0068; d) Profiled mullion element \#0121

(Authors' drawings)

To obtain the profiles of the four gothic fragments, ca. 1250 points from 3 positions were measured. Time requirement was approximately 2.3 hours for measuring, and ca. 10 additional hours for data processing. The equipment for the survey was a Leica TCR407 power total station (Fig. 6).

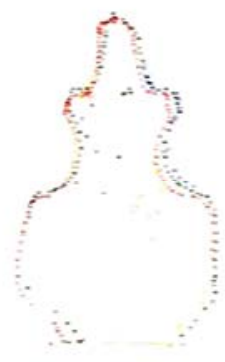

a)

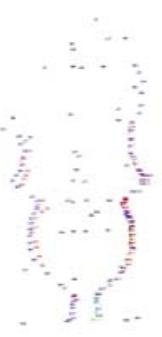

b)

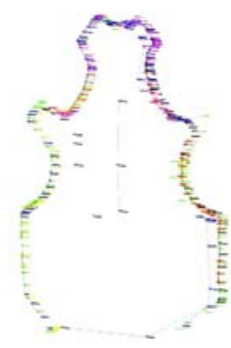

c)

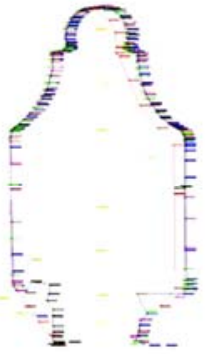

d)

Fig. 6. CAD drawings of the four gothic fragments based on total station survey: a) Profiled rib element \#0048; b) Profiled rib element \#0051; c) Profiled rib element \#0068; d) Profiled mullion element \#0121 (Authors' drawings)

\section{Experiences of the case study}

The results of the two survey methods provided valuable experiences, especially the comparison of the manually and by laser measured profiles. The CAD drawings of two types do not cover each other completely; their difference alternates in an interval from 0 to $1.6 \mathrm{~cm}$. This high discrepancy is due to several factors discussed below. By the consideration of these and using the superposition of the contours provide a satisfactory result for further geometrical analysis. 
As the reasons for the errors of survey a group of aspects can be mentioned. However, the digital reproduction of these items is likely to be simple the realization of the measure raises difficulties. First of all, the remains of painting and mortar partially from the original finishing of the ribs or from secondary use can modify the result. These are all historical evidences thus not possible to remove in favor of the survey. Furthermore, the carving accuracy of the stones is hardly adequate, especially in the case of the three ribs (\#0048, \#0051, \#0068), even though the precision of the profile played a major role in the assemblage of the ribs, because very accurate joints were needed. On the one hand, probably the building method of vaults can explain the anomalies of the profiles along the stones. Before carving the profile, the piece of stone was rough-hewn with the cutting planes of the proper angle shaped on both ends then the draft of the profile contour was scratched on these planes. In the example \#0051 some of these scratches are still clearly visible. The stonemason tried to maintain the profile following the directrix along the rib, but minor deviations were inevitable in the process of this three-dimensional figuration without an actual line to follow. It must be taken into account, that while carving elements with a straight axis (\#0121) keeping the profile was obviously easier than in case of bent elements (\#0048, \#0068), therefore the deviations are more likely at the latter, so these have to be measured more carefully, with attention of the differences in profile. It can be assumed that the profile closest to the ideal is always the one that could be measured on the joints. Unluckily, these are the parts most exposed to deterioration - practically never remaining intact in case of fragments. In the present case the deformation of the stones is due to their later usage. The medieval parts of the Royal Palace of Buda Castle disappeared during the Great Turkish War in the $17^{\text {th }}$ century and the majority of the gothic stones had been reused as building material, often mutilated to fit in their new positions.

The stone type of the three ribs is much softer than the mullion's (\#0121) (because of its outdoor position and the structural requirements), so their large-scale abrasion is obvious. It is also the consequence of the secondary utilization, that in most of the cases no entire cross section can be found along the elements, which makes the measure more difficult. The optimal outcome of the survey would be several cross sections of one stone, the superposition of which could provide the most precise profile. By manual survey, the drawing always represents an ideal section instead of a real one, while the visible imperfections of the fragment are automatically ignored (Fig. 4). However, this 'ideal' form is hypothetic and the preconceptions of the researcher can be wrong. Constructing the drawings by a computer aided program the predefined character of the profiles is more obvious (Fig. 5). By the total station surveys the cross sections are taken throughout several planar as the final profile have to be created by the superposition of different parts.

Regarding the measure itself the margin of error has to be considered. Manual survey has its obvious limits as each dimensions cannot be measured correctly, not mentioning again the partial imperfections of the fragments. Basically laser survey is appropriate for the measurement in bigger scale, like whole buildings as its margin of error might be even in millimeters. In case of details however this accuracy rarely means the efficacy of the analysis. The diameter of the laser ray of the total station is relatively big compared to the featuring dimensions of the stones and the measure of sharp edges is practically impossible. The angle of the incidence of the ray also can 
modify the accuracy of the result, because if it reaches the surface under a quite acute angle, the assumed center point of the laser may differ from the spot intended to aim at. As the measure can hardly be realized from one position in order to get enough data from all sides of the item, the adjustment of the parts of the sets of point represents the weak point of the process. In case of architectural details, the tiniest errors in the measurement of reference points have considerable consequences on the result. The direction of the planar, which the points are projected on for having orthogonal profile drawings, plays also a critical role. Without exact three points for the definition of this planar the projection stays uncertain, which is more complicated in the case of rib elements having a curved directrix. For instance, however the curve of the stone \#0048 is visible, the correct constructing of the curvature is problematic. Repeating the definition of the arch by three parallel points from the same angle of the profile, each time results a different radius of curvature (Fig. 7). In theory, being a vaulting element the stone \#0068 also has a curve, in practice however this curvature is neither visible nor measurable. This might be explained by the former position of the stone if it would be a part of the vault of a quite small bending where the curvature of the rib elements could be converged to zero. Furthermore, the length of the stone $(27.73 \mathrm{~cm})$ is relatively short to the assumed arch. Nevertheless, this problem of curvature calls the attention to the possibility that in some cases of vaulting design the stonemasons approached the arches with straight sections. In order to verify this question, a representative amount of rib elements should be surveyed. In the case of the visibly bent stones the difference between the several profile contours as the results of the measures theoretically would be bigger than in the case of straight ones, like a mullion, a cornice or a plinth. This anomaly is negligible in our case study of the stone \#0048, which can be explained by the inaccuracy and fragmentary status of the item.

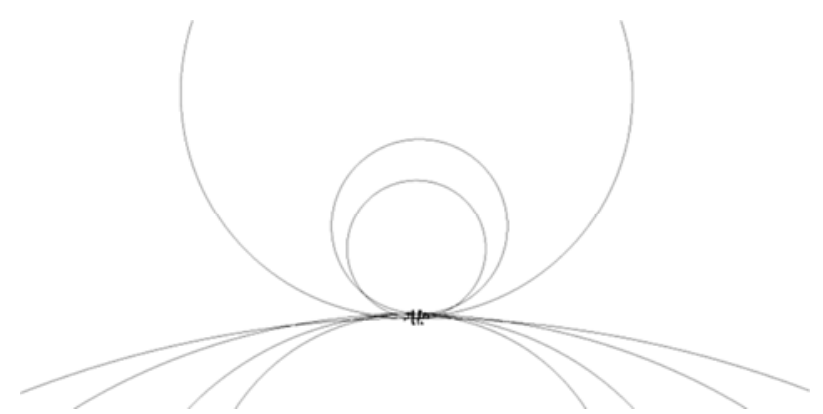

Fig. 7. Repeated definition of the curvature of stone \#0048 using three parallel points from the same angle of the profile (Authors' drawing)

\section{Conclusion}

Despite of the fact that the results of the two surveys were uncertain, the ensemble of the profile drawings can provide an appropriate basis for the further geometrical research. As a further intention of the research first and foremost the main dimensions are to be found for instance the enframing rectangles. Thus the original medieval unit 
can be concluded, or furthermore the geometrical method of triangulation or quadratic constructing. Utilizing both the sections measured manually and by laser total station and having interpolated these contours, sufficient data for further analysis could be collected.

\section{Acknowledgements}

The authors would like to express their special thanks to András Végh, director of Castle Museum of the Budapest History Museum for providing access to the medieval stone collection, as well as to the Department for History of Architecture and of Monuments of Budapest University of Technology and Economics.

\section{References}

[1] Bereczki Z. Hans Hammer's sketchbook and the building technology of the late Gothic: A preliminary assessment, Pollack Periodica, Vol. 8, No. 2, 2013, pp. 3-12.

[2] Shelby L. R. Medieval Mason's Templates, The Journal of the Society of Architectural Historians, Vol. 30, No. 2, 1971, pp. 140-154.

[3] Bork R. Dynamic unfolding and the conventions of procedure: Geometric proportioning strategies in Gothic architectural design, Architectural Histories, Vol. 2, No. 1, 2014, Art. 14.

[4] Holton A. The working space of the Medieval Master Mason: the tracing houses of York Minster and Wells Cathedral, Proceedings of the Second International Congress on Construction History, Ed. by Dunkeld M., Campbell J., Louw H., Tutton M., Addis B., Powell C., Thorne R. Cambridge, Construction History Society, 2006.

[5] Böker J. J. Architektur der Gotik. Bestandskatalog der weltgrößten Sammlung an gotischen Baurissen (Legat Franz Jäger) im Kupferstichkabinett der Akademie der Bildenden Künste Wien, Pustet, Salzburg, 2005.

[6] http://classes.bnf.fr/villard/feuillet/, (last visited 30 December 2016).

[7] Papp S. Constructions of the Royal Court in Hungary 1480-1515 (in Hungarian) Balassi Kiadó, Budapest, 2005, pp. 153-160.

[8] Nagy E. Catalogue of carved stones from the Medieval Royal Palace of Buda I (in Hungarian), manuscript, 1994.

[9] Várnai D. Morphological development of Medieval Vault Ribs in Buda Castle (in Hungarian), Budapest Régiségei, Vol. 16, 1955, pp. 363-371.

[10] Somogyi Á., Barsi Á., Molnár B., Lovas T. Crowdsourcing based 3D modeling, International Archives of Photogrammetry and Remote Sensing, Vol. 41, 2016, pp. 587-590.

[11] Bereczki Z. The structural analysis of the (demolished) medieval system of St. Elisabeth's Church in Kassa, Pollack Periodica, Vol. 9. No. 3, 2014, pp. 127-138.

[12] Bauer, T. Lauterbach, J. Nußbaum, N. Benedikt Rieds Schlingrippengewölbe auf der Prager Burg. Entwurf - Steintechnik - Kontext. In: InSitu Vol. 7, 2015, pp. 59-76. 